\title{
Analysis of the Negative Impacts of Coffee Husk on the Local Environment
}

Berhanu Tolessa Amena ( $\square$ roberabirhanu2015@gmail.com )

Addis Ababa Science and Technology University https://orcid.org/0000-0001-5604-9098

\section{Holm Altenbach}

Otto-von-Guericke-University Magdeburg: Otto von Guericke Universitat Magdeburg

Getachew Shunki Tibba

Addis Ababa Science and Technology University

Hirpa G. Lemu

University of Stavanger: Universitetet i Stavanger

\section{Research}

Keywords: Coffee husk, Caffeine, Chlorogenic, Tannins, and UV/Vis Spectrophotometer

Posted Date: January 4th, 2022

DOI: https://doi.org/10.21203/rs.3.rs-1178642/v1

License: (c) (i) This work is licensed under a Creative Commons Attribution 4.0 International License.

Read Full License 


\section{Abstract}

In a locality wherever intense low process is completed while not appropriate waste management measures, low effluents area unit the principal reason behind organic pollution. Low husk contains caffeine, tannins, and chlorogenic acid, creating it a dangerous exposed husk. The low method has been delivery environmental issues to the environment thanks to the discharge of pollution with a large quantity of organic waste. the target of this work is to research the negative impacts of low husk on the atmosphere to scale back environmental pollution in step with the planet Health Organization, one among the foremost vital problems that enterprises confront as they look for ways to limit their use of the artifact by changing it into value-add products/applications is that the harmful impact of low husk on the atmosphere (WHO).The significance of the experiment is to form low husk as an alternate resource to switch fiber. Methylene chloride liquid-liquid extraction was developed to avoid caffeine, tannin, and CGA spectral overlapping within the three hundred $-700 \mathrm{~nm}$ wavelength vary. The results indicated increment deadly materials that have an effect on the atmosphere. From the experiment performed low husk are often used as an alternate resource for getting composites for might applications and solve the environmental issues.

\section{Introduction}

Ethiopia is that the original birthplace of low and one among the main Arabica low growers within the world. Coffee process enterprises produce a substantial quantity of low husk in Ethiopia annually. However, they need been badly used, or are allowed to rot or burn in associate open field, or are improperly drop on the atmosphere and a close-by watercourse. Low is associate agricultural product that's important to the economies of coffee-producing countries across the planet. Ethiopia is currently the world's fifth largest producer and bourgeois of low [1]. low production in Ethiopia will increase on a daily basis thanks to high demand round the world; Tables one and a couple of show the number of low production and production trend at Buno Bedele zone and llubabor zone severally for the amount 20162021. Increasing low production implies that monumental quantity of low husk is generated and these enormous low husks brings environmental pollution issues like pollution, health issues, and increase the acidity of land.

Table 1. Buno Bedele zone coffee production.

\begin{tabular}{llll}
\hline Year & Production (ton) & Increase(ton) & Increase( \%) \\
\hline 2016 & 31,963 & - & - \\
2017 & 46,142 & 14,179 & 30.73 \\
2018 & 51,923 & 5,781 & 11.13 \\
2019 & 53,668 & 1,745 & 3.25 \\
2020 & 56,789 & 3,121 & 5.50 \\
2021 & 59,559 & 2,770 & 4.65 \\
\hline
\end{tabular}


Source: Buno Bedele zone Agricultural Bureau.

Table 2. Ilubabor zone coffee production.

\begin{tabular}{llll}
\hline Year & Production (ton) & Increase(ton) & Increase( \%) \\
\hline 2016 & 34,963 & - & - \\
2017 & 56,142 & 21,219 & 37.79 \\
2018 & 61,943 & 5,801 & 9.37 \\
2019 & 63,868 & 1,925 & 3.01 \\
2020 & 66,898 & 3,030 & 4.74 \\
2021 & 69,559 & 2,661 & 3.98 \\
\hline
\end{tabular}

Source: llubabor zone Agricultural Bureau.

Depending on the process technique, low process creates monumental amounts of agricultural waste, capable around $30-50 \%$ the load of the low produced [2]. Coffee provides a living for over twenty fifth of Ethiopians, either directly or indirectly. The foremost important challenge of the country is that the poor management system of a large quantity of low husk waste generated by low process industries [3]. The foremost difficult issue is that the improper disposal system of those husk wastes into the open atmosphere. Such techniques of waste disposal are important issues to communities living round the coffee process factories. Moreover, such a venturous technique of disposal has largely injured land and living species [4]. The low husk contains organic substances for bioconversion into added product. However, an oversized quantity of usage and management of low husk throughout the planet up to currently challenged by caffeine, tannins, chlorogenic, free phenols, rosmarinic that area unit terribly deadly to abundant living life. Such wastes area unit the sources of environmental pollution associated their disposal is most of the time done on an open field close to the process unit. The low husk waste disposal causes several important health issues like respiratory issues, spinning sensations, eye irritation, abdomen drawback, nausea, etc. Even today, these low husks area unit unutilized per their availabilities and disposal has been thought-about being disrespectful to the environment [5]. Coffee effluents area unit the most supply of organic pollution in associate atmosphere wherever intensive low process is practiced while not applicable by-product management systems. Environments that area unit exposed to the effluents generated from low beans process show amendment in terms of their physical, biological, and chemical behavior [5]. The indiscriminate and open disposal of waste will cause environmental degradation by introducing totally different toxicants together with significant metals within the soil and water compartments [6] [7]. Open marketing of municipal low husk or solid waste is common follow in Ethiopia, and also the drawback of solid waste disposal is one among the main issues of the community and municipalities [8] [9]. Open marketing of municipal low husk or solid waste is common follow in Ethiopia, and also the drawback of solid waste disposal is one among the main issues of the community and municipalities 
The disposal system of coffee husk in Ethiopia shown in Fig. 1 indicates the way how coffee husk is managed after being processed. The accommodated coffee husk brings environmental pollutions. The main objectives of this study are to solve the problems of automotive industries and environmental pollution by converting coffee husk to a product with value-adding to the fiber. The problems identified for this study are automotive industries with the environment and coffee husk with the environment. The problems in automotive industries are using synthetic fiber which is nowadays a global problem to environmental and costly imported from outside of the country. The other problem is the disposal system of coffee husk and not yet this resource utilized as its availability of the resource. A recent study shows that in most cities, municipal solid wastes area unit disposed of in open areas while not discriminating major residential areas, roadsides, voidance areas, rivers, riversides, and forests. This leads to the introduction into the water, soil ecology, and total to the environment [10].

\section{Literature Review}

\subsection{Compounds of ecotoxicological concern}

Many studies develop the helpful properties of low beverages together with antibacterial drug [11], antioxidant [12], anti-inflammatory, and anti-obesity [12]. However, the activity of compounds like caffeine, chlorogenic acid, and tannins into the surroundings from low waste (husk) will have severe ecotoxicological effects [13]. Though several studies have investigated caffeine concentrations in waterways toxicity information is very restricted to workplace simulations. Caffeine is that the major constituent of low that gives the processed stimulant result of low beverages, allowing maintained psychological feature perform and reduced central fatigue[14]. Caffeine is poisonous to aquatic organisms and mammalians and ends up in abnormal juvenile growth and reduced fecundity that could be a major environmental concern for higher biological process levels. Caffeine has negative effects on plants [15], flora [16], and microorganism growth[17]. Tannins area unit historically related to the animal skin tanning business and area unit prevailing in developing countries [18]. These compounds area unit most typically found within the bark of vascular plants, and to a lesser extent leaves, fruit, flowers, and seeds[19]. Tannins will be harmful, looking on the sensitivity of the organism and therefore the concentration of exposure. Chlorogenic acid could be a soluble polyphenol fashioned by the esterification of caffeic acid with quinic acid [20], that contains a superfluity of properties.

\subsection{Coffee's Life Cycle and therefore the Use of Husk Product}

Figure 2 depicts a summary schematic of the coffee cherry's post-harvest processing processes, with emphasis on the phases that contribute to the primary formation of solid reduces. Massive amounts of toxic water are also created in washing process, with a high carbon load and hence a significant environmental effect 
Coffee husks area unit composed of $58-85 \%$ of super molecule, $8-11 \%$ of proteins, $0.5-3 \%$ of lipids, $3-7 \%$ of minerals, and small quantity of bioactive compounds, like caffeine $(\sim 1 \%)$, chlorogenic acid $(\sim 2.5 \%)$ and tannins ( $5 \%)$ are gift within the low husk waste[21] [22] [23]. Several application approaches are studied for low cherry husks area unit re-utilization, as a substrate for biogas [24], [25]and alcohol production [16] biosorbents for cyanide [26], biosorbents for removal of significant metals from liquid solutions [27], biosorbents for the removal of dyes from aqueous solutions [16] [28], biosorbents for defluoridation of water [29], biosorbentsfor lead (II) [30], for getting ready activity material converts into fuel pellets or extracted for bioactive substances recovery [16], in Ethiopia, this coffee generated enormously annually from coffee processing, but it is not utilized as its availabilities. Besides, coffee husks demonstrated to be suitable candidates for a more direct utilize as substrate for edible mushrooms production [31] or compositing [32] [33] [34]preparation of briquettes [35], bio-ethanol [36] vinegar production [37] biogas production [38] production of particleboard. Low husks are used as a possible purposeful ingredient in food production (utilizing the bottom low husk as food supplementary for usage in smoothies, granolas, and juice). The value-adding process to convert coffee husk into products is a better solution for the reduction of environmental pollution and increasing utilization of coffee husk as alternative resources in the country.

\section{Materials And
3.1. Materials}

Dichloromethane (Aldrich, Germany), Caffeine (Evan, England), Tannin, Chromogenic, Sodium Hydroxide (pool, England), and distilled water were used as reagents up to the end of activities. Coffee samples (Coffee Arabica) were collected from the southwest of Ethiopia in particular from Buno Bedele and llubabor, Drying oven, Chemicals: - $\mathrm{NaOH}, \mathrm{H}_{2} \mathrm{SO}_{4}$, Distilled water, Chemicals: - Nitric acid, Sulphuric acid, Ethanol, Benzene, Acetic acid, sodium chlorite, Toluene.

\subsection{Methods}

Coffee husk fiber were washed with distilled water and then taken to an oven at $105^{\circ} \mathrm{C}$ for 24 hours to dry or exhibit the moisture of coffee husk then after treated with $10 \%$ of $\mathrm{NaOH}$ to get rid of unwanted materials from the fibers; to adjust the $\mathrm{P}^{\mathrm{H}}$ value of the fibers again treated by $3 \%$ of $\mathrm{H}_{2} \mathrm{SO}_{4}$. Coffee husk chemical composition analysis was collected, washed, dried, and milled with a laboratory electric mill (DIETZ7311) with sieve sizes of $0.150 \mathrm{~mm}$ and $0.125 \mathrm{~mm}$.

\subsection{Experimental}

Measurements were done by victimization UV/Vis photometer maalab scientific instrumentation double beam UV/Vis photometer with $1 \mathrm{~cm}$ quartz cuvette. The photometer was interfaced with its $\mathrm{pc}$ and another laboratory equipment was used sort of a water tub, autoclave, and stirrer.

For the spectrophotometric check procedure, associate degree liquid caffeine stock answer was ready by dissolving $2.91 \mathrm{mg}$ caffeine in a $100 \mathrm{ml}$. Operating answers of caffeine were after ready by precise 
dilution of the stock solution with de-ionized water. Similarly, a stock answer of caffeine was ready by dissolving $1.45 \mathrm{mg}$ of caffeine in $50 \mathrm{ml}$ of chloride and diluting it to a series of $25 \mathrm{ml}$ normal meter flasks. Every coffee sample was measured thrice and therefore the average worth and variance and relative variance was calculated.

\subsection{Sample preparation and extraction}

Coffee husk was ground with a commercial blender or milling cutter machine. The powder was sieved by test sieve with a mesh 80 and mesh 100, i.e, $0.125 \mathrm{~mm}$ and $0.150 \mathrm{~mm}$ particle size (Retsch $\circledast$, Germany). A $100 \mathrm{mg}$ of coffee husk powder was dissolved in $25 \mathrm{ml}$ of de-ionized water in a beaker and diluted to 50 $\mathrm{ml}$ with de-ionized water. Then the solution was heated in a boiling water bath at $100^{\circ} \mathrm{C}$ for two hours on a hot plate while stirring. To prepare the standard solution a commercially bought pure CGA (AldrichSigma, Germany) of $100 \mathrm{mg}$ was accurately weighed on an electronic balance and dissolved in $500 \mathrm{ml}$ of de-ionized water for preparation stock standard solution. The solution was uniformly dissolved employing a magnetic hot plate stirrer in a very dark space to limit light-weight interaction. Series of ordinary solutions were ready from the stock solution $(5,10,15,20$, and 25$) \mathrm{mgL}-1$ for CGA in de-ionized water and every one measurement were right away performed, and therefore the absorbance of every series was measured. The series solutions were ready consistent with Beer-Lambert's law. Specifically a weighted $20 \mathrm{mg}$ amount of sieved coffee husk powder was dissolved in de-ionized water in a volumetric flask up to a mark of $50 \mathrm{ml}$. Then the solutions were stirred for one hour using a hot plate magnetic stirrer and heated gently to increase the solubility of CGA in the solution, and then the solutions were filtered by a glass filter to get particles alone from the solutions. After filtration, the Extraction of CGA was performed by the liquid-liquid method. The method or procedures used to extract Chlorogenic acids and Tannin acid are similar to the procedures performed for the extraction of caffeine for coffee husk. LiquidLiquid extraction and absorption measurement procedures are used in this process.

Dichloromethane liquid-liquid extraction was developed to avoid caffeine, tannin, and CGA spectral overlapping in the $300-700 \mathrm{~nm}$ wavelength range. A Sample solution prepared above ( $50 \mathrm{~mL}$ solution) was mixed with $50 \mathrm{~mL}$ dichloromethane resulting $100 \mathrm{ml}$ solution of samples. The solution was stirred for 30 min where a layer was formed with caffeine making the upper layer and CGA lower layer. From the residue of CGA collected and measured, absorption of CGA was measured by using a double beam UV/Vis spectrophotometer (maalab, India) with a wavelength range of $190-1100 \mathrm{~nm}$ from were which CGA concentration was calculated consistent with brewage Lambert's Law at the utmost wavelength. Once the CGA caffeine and phenol concentration were calculated from the absorbance of the measured sample answer consistent with brewage Lambert's Law at most wavelength, the CGA contents in low husk were calculated by victimization the subsequent equations.

\section{$A=\llbracket c l(1)$}

Where $\mathrm{A}$ is that the absorbance of the answer, $\mathrm{c}$ is that the $\mathrm{M}$ of the matter (mole/m3), is that the molar worth derived absorptance ( $\mathrm{m} 2$ mole -1$)$, and $\mathrm{I}$ is that the shaft of light length $(\mathrm{m})$. The molar decadic absorption factor constant, that is constant for a selected molecule at a given specific wavelength, is 
usually expressed as gamma hydroxybutyrate the molar absorption factor at associate degree optical phenomenon most. Caffeine extraction yielded 0.512 weight unit $\mathrm{dm}^{-3}$ and 0.510 weight unit $\mathrm{dm}^{-3}$, respectively.

$E=E($ excited $)-E($ ground $)=h v=h c / \lambda(2)$

\section{Results And Discussion}

\subsection{The study of absorption spectra}

Initially, an investigation was created concerning the quality of ways for making ready a processed binary compound extract of the occasional husk sample. The primary spectrophotometric measuring for the binary compound extract, with none drop of alkali resolution, indicated that everyone spectra had a most at that the absorption peak of alkaloid was expected. For the spectrophotometric determination of alkaloid, the wavelengths were investigated at intervals the interval the $300-700 \mathrm{~nm}$. The wavelength of one intense absorption placed within the ultraviolet illumination vary at $\lambda \max =301 \mathrm{~nm}$ and for the determination of CGA the wavelengths were as investigated at intervals the interval $300-700 \mathrm{~nm}$. The wavelength of one intense absorption is found within the ultraviolet illumination vary at $\lambda \max =298 \mathrm{~nm}$, as shown in Fig. 3.

\subsubsection{Determination of Caffeine in Dichloromethane Extracts}

These extraction procedures have the profit that meddlesome substances like chlorogenic acid, and trigonelline acid, and phenol that square measure sometimes found in occasional husk related to alkaloid, square measure utterly removed, because the former is fastened by the solution of zero. $1 \mathrm{M}$ $\mathrm{NaOH}$. Trigonelline, Caffeic acid, Chlorogenic acid, Associate in Nursingd phenol acid being insoluble in methylene chloride remained in a solution and this procedure didn't cause interference. The investigations of the ultra-violet absorption spectra of methylene chloride extracts indicated that everyone the spectra have a most of $298 \mathrm{~nm}$ that square measure an equivalent as alkaloid. Uv/Vis spectra of alkaloid in methylene chloride extracts were found to be specific as no meddlesome peaks were discovered throughout spectrophotometric measuring of alkaloid in methylene chloride extracts, because it was additionally nominative by the height purity in Fig. 4 .

A linear operate increase within the absorbance was discovered because the concentration of alkaloid was varied between $2.5 \times 10-5$ to $1.25 \times 10-4$ weight unit dm-3. Similarly, absorbance measuring was allotted victimization 1.0 10-4 weight unit dm-3 normal alkaloid resolution prepared by diluting a stock resolution with twenty five mil methylene chloride. The result indicated a most absorption at $\lambda \max =$ $301 \mathrm{~nm}$ as indicated in Fig. 4. 
To establish the range in which the linearity between absorption power and concentration exists for chlorogenic acid different concentrations of standard solutions of CGA were prepared. To remove interfering bands, an aqueous solution of $0.1 \mathrm{M} \mathrm{NaOH}$ was used as the modifier of the methods for the activity. With the dropwise addition of $0.1 \mathrm{M} \mathrm{NaOH}$, the overlapped bands start to resolve. After successive drops, into the aqueous extract of the coffee husk solution, spectra bands changed. The obtained results are $0.321 \mathrm{~mol} \mathrm{dm}^{-3}$ and $0.306 \mathrm{~mol} \mathrm{dm}^{-3}$.

\subsubsection{Determination of tannin in aqueous extracts}

Tannin extract from coffee husk waste biomass has been demonstrated to be extremely promising for possible application as alternative resource for composite materials. Solvents such as water, ethanol, and dichloromethane are used to obtain them. Tannic acid, whose concentration is phenols, was the most prevalent phenolic component in all of these extracts.

A linear function increase in the absorbance was observed as the concentration of caffeine was varied between $2.5 \times 10^{-5}$ to $1.25 \times 10^{-4} \mathrm{~mol} \mathrm{dm}^{-3}$. Similarly, absorbance measurement was carried out using 1.0 $10^{-2} \mathrm{~mol} \mathrm{dm}^{-3}$ standard caffeine solution ready by diluting a stock solution with $25 \mathrm{ml}$ dichloromethane. The result indicated a maximum absorption at $\lambda \max =300 \mathrm{~nm}$ as indicated in Fig. 5 . The graph indicated below looks like due to the methods used to analysis the tannin and the fiber characteristics.

\subsection{Calibration curves}

The standardization curve for alkaloid in methylene chloride was engineered by plotting absorbance points as an operate of the analyte concentration. Every price of the standardization graphs was the

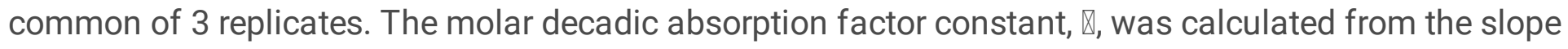
of the standardization curves.

Beer's law was valid within the concentration vary from 2.5 x10-5 to $1.25 \times 10-4$ weight unit dm-3 alkaloid solutions ready in de-ionized water and methylene chloride. The relation of coefficients showed a decent linear relationship between absorbance and alkaloid concentration. To gauge the exactitude and detection limit, a $2.5 \times 10-5$ weight unit dm-3 normal alkaloid resolution in every solvent was used. The relative variance for 3 replicate measurements of alkaloid was $4.21 \%$ and $3.23 \%$ in water and methylene chloride severally. The limit of detection (three times the blank variance divided by the slope of the equation) was $2.10 \mathrm{mg} / \mathrm{l}$ and $1.63 \mathrm{mg} / \mathrm{l}$ in water and methylene chloride severally.

The developed Spectrophotometric methodology for determinant alkaloid, chlorogenic, and tannins in occasional husk has been tested for real samples. Several studies indicate that trigonelline, chlorogenic, tannins, and alkaloid acids square measure the first interferes within the quantitative determination of alkaloid and chlorogenic in occasional husk samples by victimization UV/Vis Spectrophotometry. However, to induce the correct price, it's higher to use Higher-Performance Liquid -chromatography (HPLC). The parts of binary compound extracts were used for spectrophotometric measurements created upon convenient diluted solutions before extraction of alkaloid and CGA with methylene chloride. The 
binary compound extracts were treated with a drop-wise solution of zero. $1 \mathrm{M} \mathrm{NaOH}$. The spectrophotometric measurements for binary compound extracts indicated that well d resolved with dropwise alkali resolution. However, complete elimination of those acids wasn't achieved. However to induce the correct price, it's higher to use Higher-Performance Liquid -chromatography (HPLC). The spectrophotometric methodology used for evaluating alkaloid was modified for the end removal of interferes from binary compound extracts. The sample was treated as indicated in sample preparation. Within the starting, the finding was created concerning the quality of the tactic for making ready a transparent binary compound extract of the sample. The primary spectrophotometric measuring for binary compound extract, with none drop of alkali resolution all spectra had a most at the absorption peak of alkaloid, was expected. The bands square measure vividly seen within the spectral bands of occasional a sample is dissolved in de-ionized water.

The planned methodology was utilized to guage the alkaloid quantity in occasional samples victimisation binary compound extracts. To induce this occasional sample dissolved in water. The samples of every occasional husk sample were analyzed by the specified methodology, by mensuration the ultimate quantity of every extract. The outcomes obtained from the specified methodology were compared to the literature extraction methodology utilizing methylene chloride extracts for analysis of alkaloid, CGA within the sample. the number of pure alkaloid, CGA, and phenol were determined at the wavelength of most absorption and points of the ascending and downward parts of the curve equal from the most. The outcomes of the determination of those acids in occasional husk samples were achieved once subtracting the interferents peak from the entire alkaloid, tannin, and CGA spectra.

\section{Conclusion}

The study investigated the dangerous outcomes of coffee husk on the ecosystem. In this technique, coffee husk extracts generated utilizing Liquid- Liquid extraction and absorption measuring techniques are employed. The presence of greater acids located in coffee husk is an exception to this rule. Similarly, in addition to an excessive attention of caffeine, CGA, and tannin, all espresso husk extracts were observed to be high in phenolic chemicals, which are very toxic to the environment. Analyzing the toxic substances of espresso husk helps us to specify the application place of the fiber. Using this coffee husk as a choice aid for value-adding applications is a tremendous mechanism to reduce their wastage as a landfill. The pollutant in coffee husk waste has been indicated to have sufficient concentration, which is toxic to the environment.

These factors have negative affects on the environment and additionally human beings; as a consequence causing many indispensable health problems like spinning sensation, eye, ear, and pores and skin irritation, belly pain, nausea, and breathing troubles amongst the residents of nearby areas. So, there is a want to curb this hassle through revolutionary and eco-friendly techniques. Therefore, it is endorsed that the negative disposal system barring pretreatment and much less consideration of a big amount of sources is now not supported. The investigation of ant-physiological elements observed in espresso husk has expanded notably in recent years, but more work has to be carried out in order to 
detoxify espresso husk and gather a novel cloth and affordable supply for composites. Coffee husk, which is now a waste product with little added-value, might emerge as a surprisingly sought-after commodity with a excessive added fee in the composites world. However, the acid content of agricultural wastes substances depending on the kind and geographical place. In order to limit immoderate acids that have an effect on the performance of the material, it is essential to make surface remedy of the fiber. Moreover, it is better to use Higher-Performance Liquid-chromatography (HPLC) for contrast and to get precision and accurate results.

\section{Declarations}

\section{Acknowledgements}

I would like to thank Adama Science and Technology University biology and Chemistry labs for supported me on this study. Miss. Emabet Geteneh is greatly acknowledged for this research work.

\section{Conflicting Interests}

The author (s) declared no potential conflicts of interest with respect to the research, authorship, and / or publication of this article.

\section{Funding}

The author (s) received no financial support for the research, authorship, and /or publication of this article.

\section{Authors Contributions:}

The idea, experimental work, the analysis of data, and the writing throughout the work was carried out by Berhanu Amena, Examination and correction by Holm Altenbach, Getechew Tibba, and Hirpa Lemu, Supervision throughout the work was carried out by Holm Altenbach and Getechew Tibba.

\section{Data Availability Statement:}

The data presented in this study are available on request from the corresponding author.

\section{References}

[1] A. G. Woldesenbet, B. Woldeyes, and B. S. Chandravanshi, "Characteristics of wet coffee processing waste and its environmental impact in Ethiopia," Int. J. Res. Eng. Sci. 2, 1-5 (2014).

[2] L. Huang, B. Mu, X. Yi, S. Li, and Q. Wang, "Sustainable Use of Coffee Husks For Reinforcing Polyethylene Composites,” J. Polym. Environ. 26, 48-58 (2018). 
[3] D. P. P. Navia, R. J. M. de Velasco, and J. L. C. Hoyos, "Production and evaluation of ethanol from coffee processing by-products," Vitae. 18, 287-294 (2011).

[4] P. S. Murthy and M. Madhava Naidu, "Sustainable management of coffee industry by-products and value addition - A review," Resour. Conserv. Recycl. 66, 45-58 (2012).

[5] H. Beyene and S. Banerjee, "Assessment of the Pollution Status of the Solid Waste Disposal Site of Addis Ababa City with Some Selected Trace Elements, Ethiopia," World Appl. Sci. J. 14, 1048-1057 ( 2011).

[6] A. A. Kebede, D. D. Olani, and T. G. Edesa, "Heavy Metal Content and Physico Chemical Properties of Soil around Solid Waste Disposal Sites," Am. J. Sci. Ind. Res.7, 129-136 (2016).

[7] Y. Birhanu, "Assessment of Solid Waste Management Practices and the Role of Public Participation in Jigjiga Town, Somali Regional State, Ethiopia," Int. J. Environ. Prot. Policy. 3, 153 ( 2015).

[8] M. Gedefaw, "Assessing The Current Status Of Solid Waste Management Of Gondar Town Ethiopia," Int. J. Sci. Technol. Res. 4, 28-36 ( 2015).

[9] A. A. Mengist Hailemariam, "Solid waste management in Adama , Ethiopia: Aspects and challenges," Integr. Dev. Water Supply Sanit. 8, 670-676 (2014).

[10] M. C. Echeverria and M. Nuti, "Valorisation of the Residues of Coffee Agro-industry: Perspectives and Limitations," Open Waste Manag. J. 10, 13-22 (2017).

[11] N. Meckelburg et al., "Antibacterial effect of coffee: Calcium concentration in a culture containing teeth/biofilm exposed to Coffea Canephora aqueous extract," Lett. Appl. Microbiol. 59, 342-347 (2014).

[12] H. Jia et al., "Coffee intake mitigated inflammation and obesity-induced insulin resistance in skeletal muscle of high-fat diet-induced obese mice," Genes Nutr. 9, 389.(2014).

[13] A. S. Fernandes et al., "Impacts of discarded coffee waste on human and environmental health," Ecotoxicol. Environ. Saf.141, 30-36(2016).

[14] J. M. Kalmar and E. Cafarelli, "Central fatigue and transcranial magnetic stimulation: Effect of caffeine and the confound of peripheral transmission failure," J. Neurosci. Methods. 138, 15-26 (2004).

[15] P. Mohanpuria and S. K. Yadav, "Retardation in seedling growth and induction of early senescence in plants upon caffeine exposure is related to its negative effect on Rubisco," Photosynthetica. 47, 293-297 (200).

[16] C. H. Miyashira, D. G. Tanigushi, A. M. Gugliotta, and D. Y. Santos, "Influence of caffeine on the survival of leaf-cutting ants Atta sexdens rubropilosa and in vitro growth of their mutualistic fungus," Pest Manag. Sci. 68, 935-940 (2012). 
[17] W. Sledz et al., "Antibacterial activity of caffeine against plant pathogenic bacteria," Acta Biochim. Pol. 62, 605-612 (2015).

[18] E. De Nicola et al., "Vegetable and synthetic tannins induce hormesis/toxicity in sea urchin early development and in algal growth," Environ. Pollut. 146, 46-54 (2007).

[19] B. Janissen and T. Huynh, "Chemical composition and value-adding applications of coffee industry by-products: A review," Resour. Conserv. Recycl. 128, 110-117 (2017).

[20] M. T. Moore, S. L. Greenway, J. L. Farris, and B. Guerra, "Assessing caffeine as an emerging environmental concern using conventional approaches," Arch. Environ. Contam. Toxicol. 54, 31-35 ( 2008).

[21] T. G. Toschi, V. Cardenia, G. Bonaga, M. Mandrioli, and M. T. Rodriguez-Estrada, "Coffee silverskin: Characterization, possible uses, and safety aspects," J. Agric. Food Chem. 62, 10836-10844 ( 2014).

[22] L. Blinová, M. Sirotiak, A. Bartošová, and M. Soldán, “FACULTY OF MATERIALS SCIENCE AND TECHNOLOGY IN TRNAVA REVIEW: UTILIZATION OF WASTE FROM COFFEE PRODUCTION," 25, 91-101 ( 2017).

[23] B. M. Gouvea, C. Torres, A. S. Franca, L. S. Oliveira, and E. S. Oliveira, "Feasibility of ethanol production from coffee husks," Biotechnol. Lett.31, 1315-1319 (2009).

[24] M. D. Ulsido, G. Zeleke, and M. Li, "Biogas potential assessment from a coffee husk: An option for solid waste management in Gidabo watershed of Ethiopia," Eng. Rural Dev. 15, 1348-1354 ( 2016).

[25] J. Akinbomi, T. Brandberg, S. A. Sanni, and M. J. Taherzadeh, "Development and Dissemination Strategies for Accelerating Biogas Production in Nigeria," BioResources. 9, 5707-5737 (2014).

[26] O. Sahu, "Bioethanol Production by Coffee Husk for Rural Area," Adv. Res. J. Biochem. Biotechnol. 1, $1-5,(2014)$.

[27] Mebrahtom Gebresemati, Nigus Gabbiye, and O. Sahu, "Sorption of cyanide from aqueous medium by coffee husk: Response surface methodology," J. Appl. Res. Technol.15, 27-35 (2017).

[28] W. E. Oliveira, A. S. Franca, L. S. Oliveira, and S. D. Rocha, "Untreated coffee husks as biosorbents for the removal of heavy metals from aqueous solutions," J. Hazard. Mater. 152, 1073-1081 (2008).

[29] N. Ahalya, M. N. Chandraprabha, R. D. Kanamadi, and T. V Ramachandra, "Adsorption of Fast Green on to Coffee Husk," J. Chem. Eng. Res. 2, 201-207 ( 2014).

[30] S. Berhe, D. Ayele, A. Tadesse, and A. Mulu, "Adsorption Efficiency of Coffee Husk for Removal of Lead ( II ) from Industrial Effluents: Equilibrium and," 5, 1-8 (2015). 
[31] W. S. Wan Ngah and M. A. K. M. Hanafiah, "Removal of heavy metal ions from wastewater by chemically modified plant wastes as adsorbents: A review," Bioresource Technology. 98, 3935-3948 (2008).

[32] B. Chala, H. Oechsner, S. Latif, and J. Müller, "Biogas potential of coffee processing waste in Ethiopia," Sustain. 10, 1-14 ( 2018).

[33] R. Salomone, "Life cycle assessment applied to coffee production: investigating environmental impacts to aid decision making for improvements at company level," 1, 295-300 (2003).

[34] C. Husk and F. Alemu, "Cultivation of Shiitake Mushroom ( Lentinus edodes ) on," 3, 64-70, (2015).

[35] N. A. Dzung, T. T. Dzung, V. Thi, and P. Khanh, "Evaluation of Coffee Husk Compost for Improving Soil Fertility and Sustainable Coffee Production in Rural Central Highland of Vietnam," 3, 77-82 (2013).

[36] G. J. Miito and N. Banadda, "A short review on the potential of coffee husk gasification for sustainable energy in Uganda," F1000Research.6, 1-13 (2017).

[37] S. A. Bekalo and H. W. Reinhardt, "Fibers of coffee husk and hulls for the production of particleboard," Mater. Struct. Constr.43, 1049-1060 (2010).

[38] A. Pandey, C. R. Soccol, P. Nigam, D. Brand, R. Mohan, and S. Roussos, "Biotechnological potential of coffee pulp and coffee husk for bioprocesses," Biochem. Eng. J. 6, 153-162 (2000).

\section{Figures}

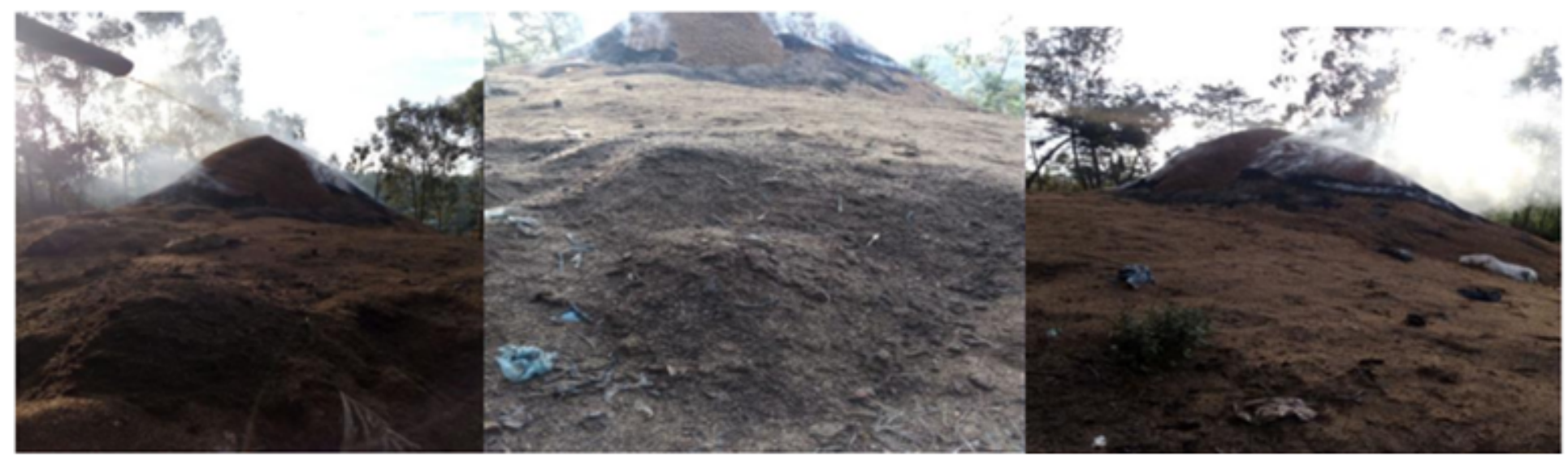

Figure 1

Coffee husk disposal system. 


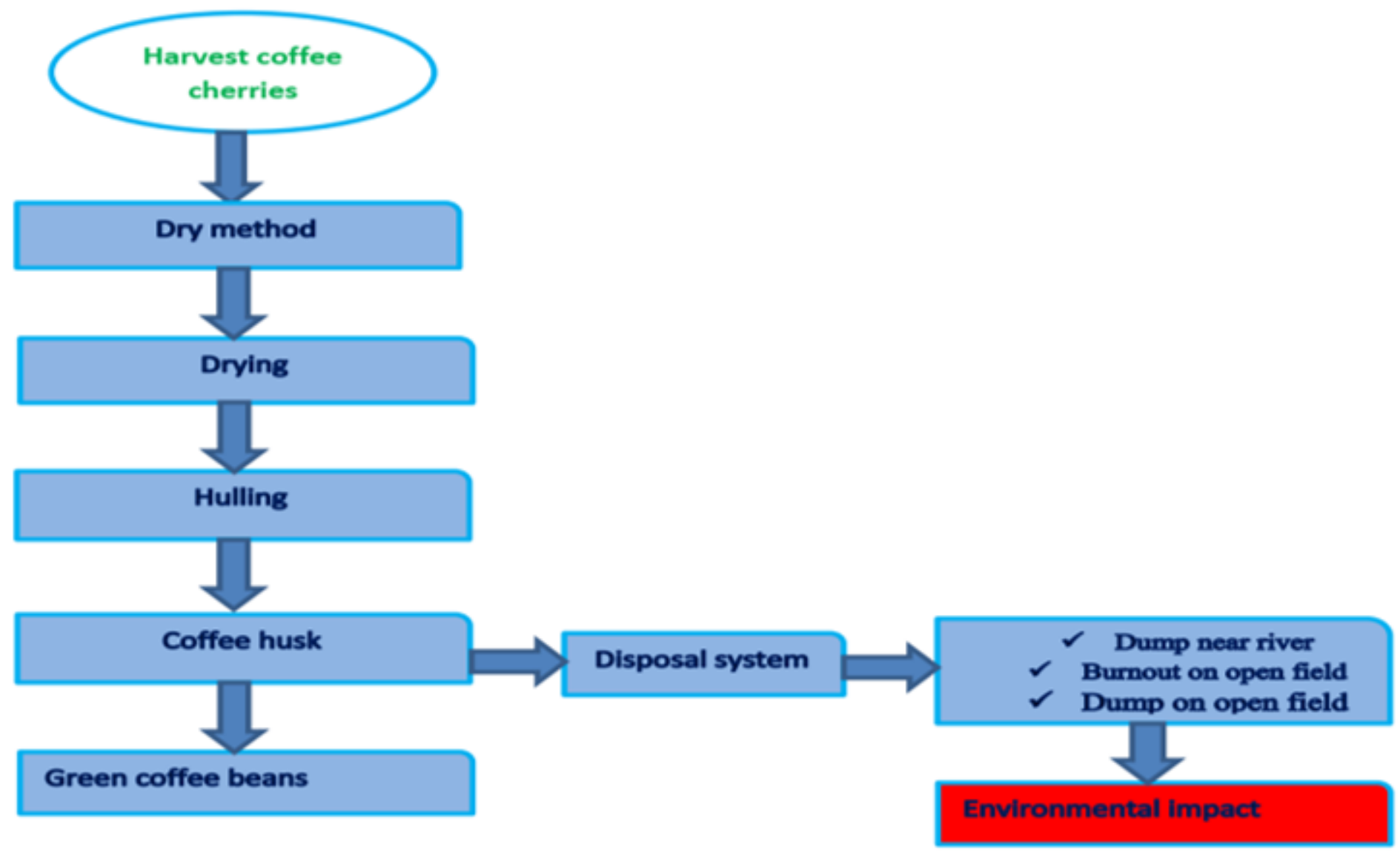

Figure 2

The life cycle of coffee husk production steps.

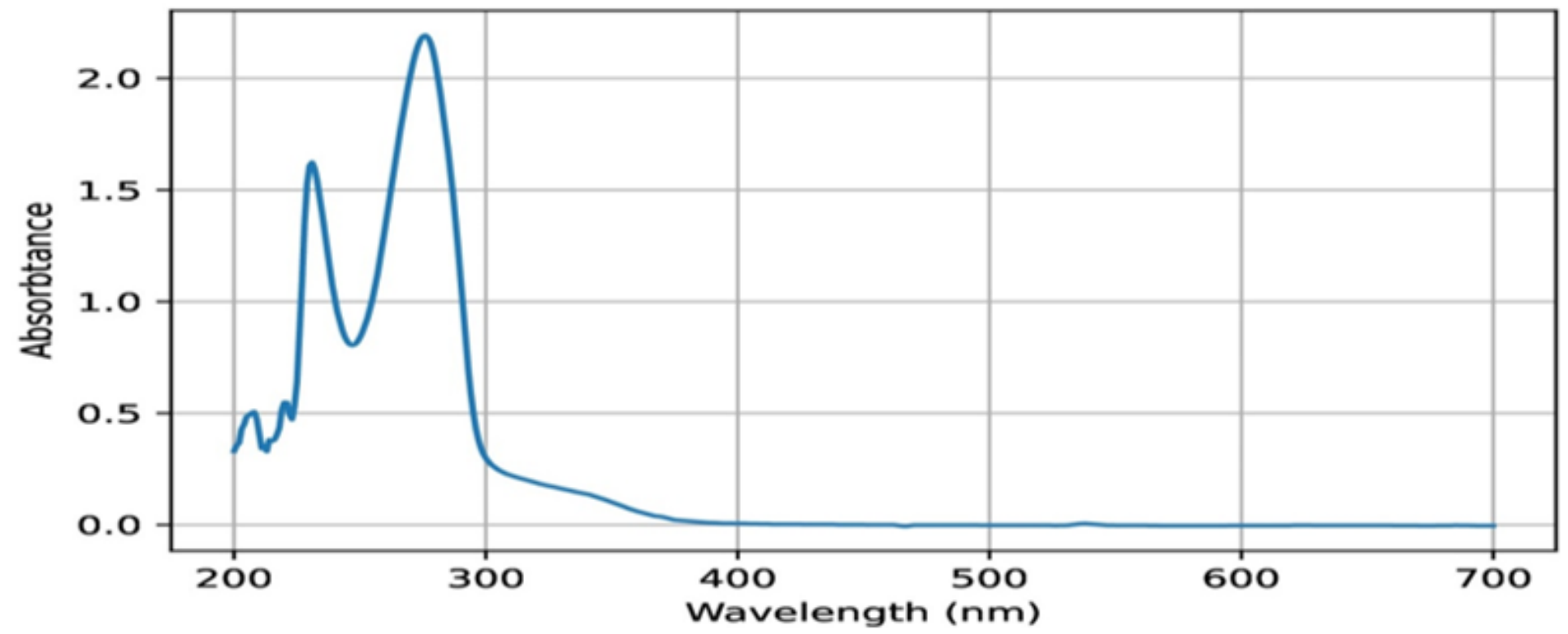

Figure 3 
UV/Vis spectrum of Caffeine in Dichloromethane.

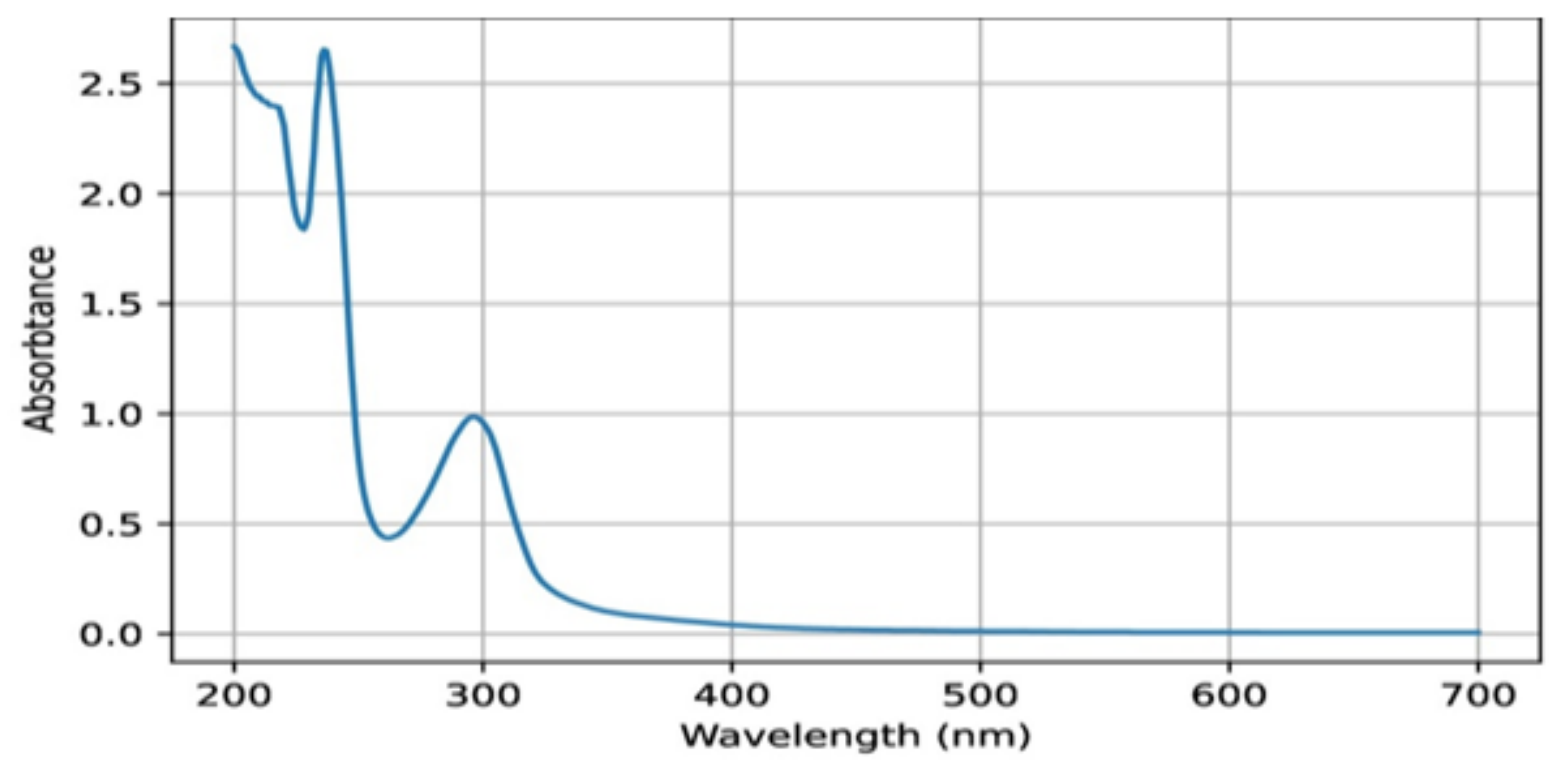

Figure 4

UV/Vis spectrum of CGA in Dichloromethane.

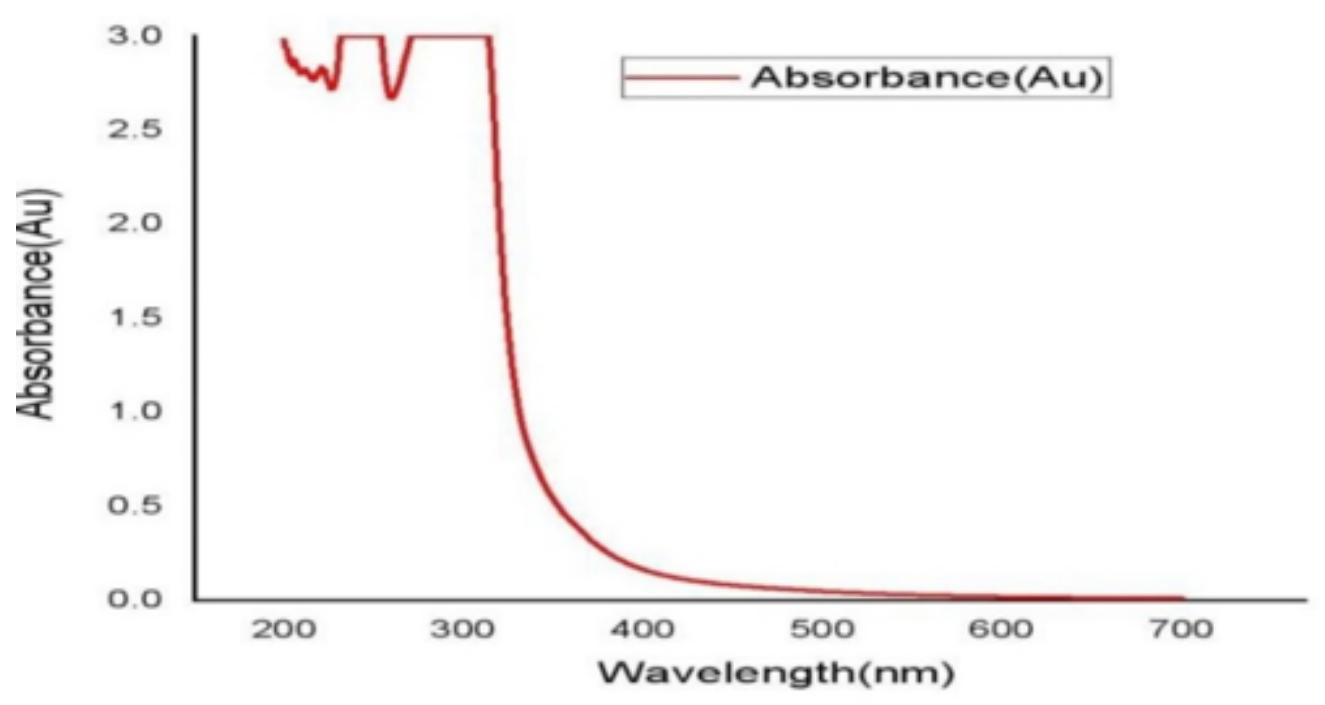

Figure 5

Absorption spectra of aqueous extracts of tannin in coffee husk fiber. 


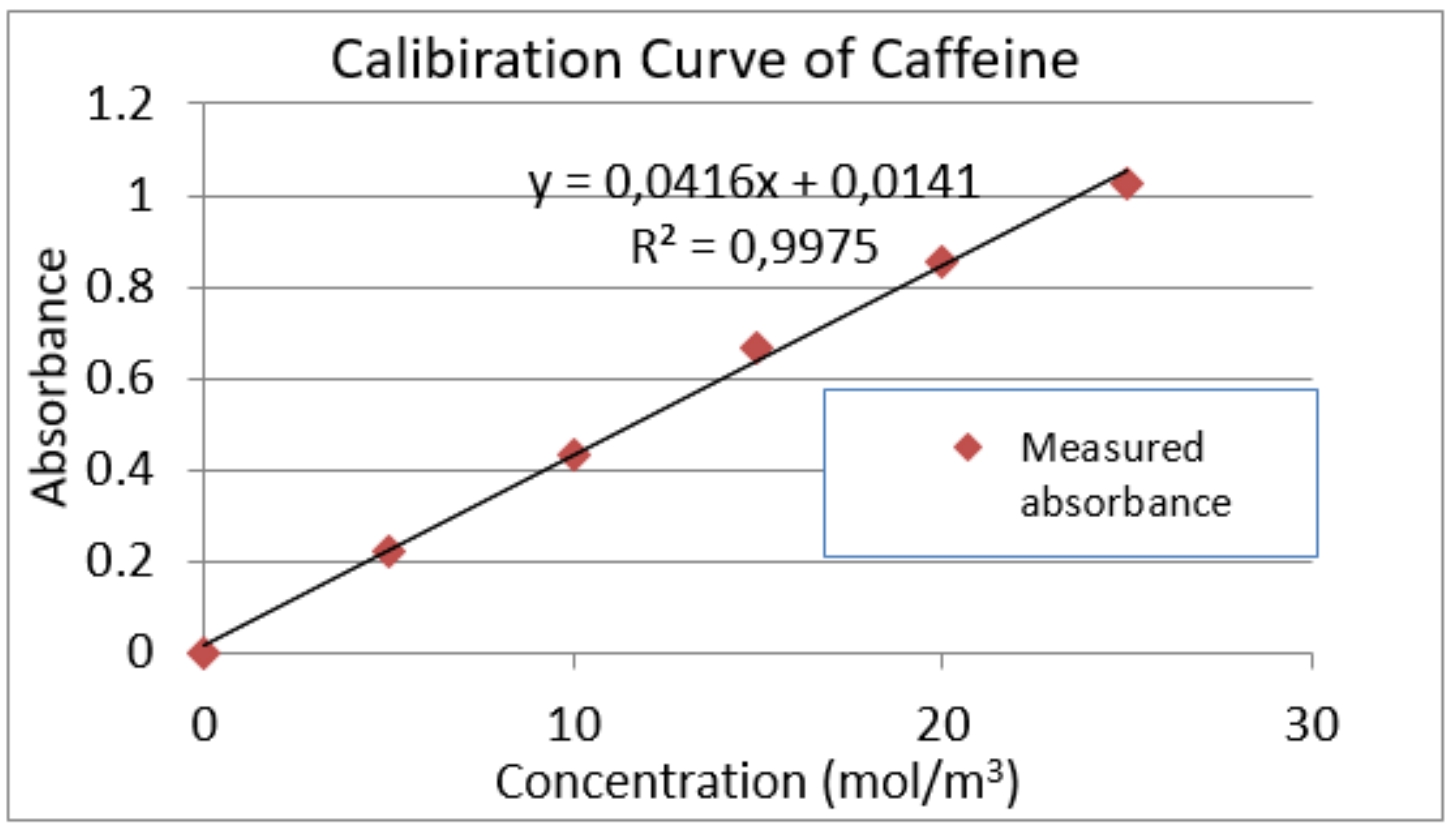

Figure 6

Linear plot of concentration versus Absorbance in Dichloromethane.

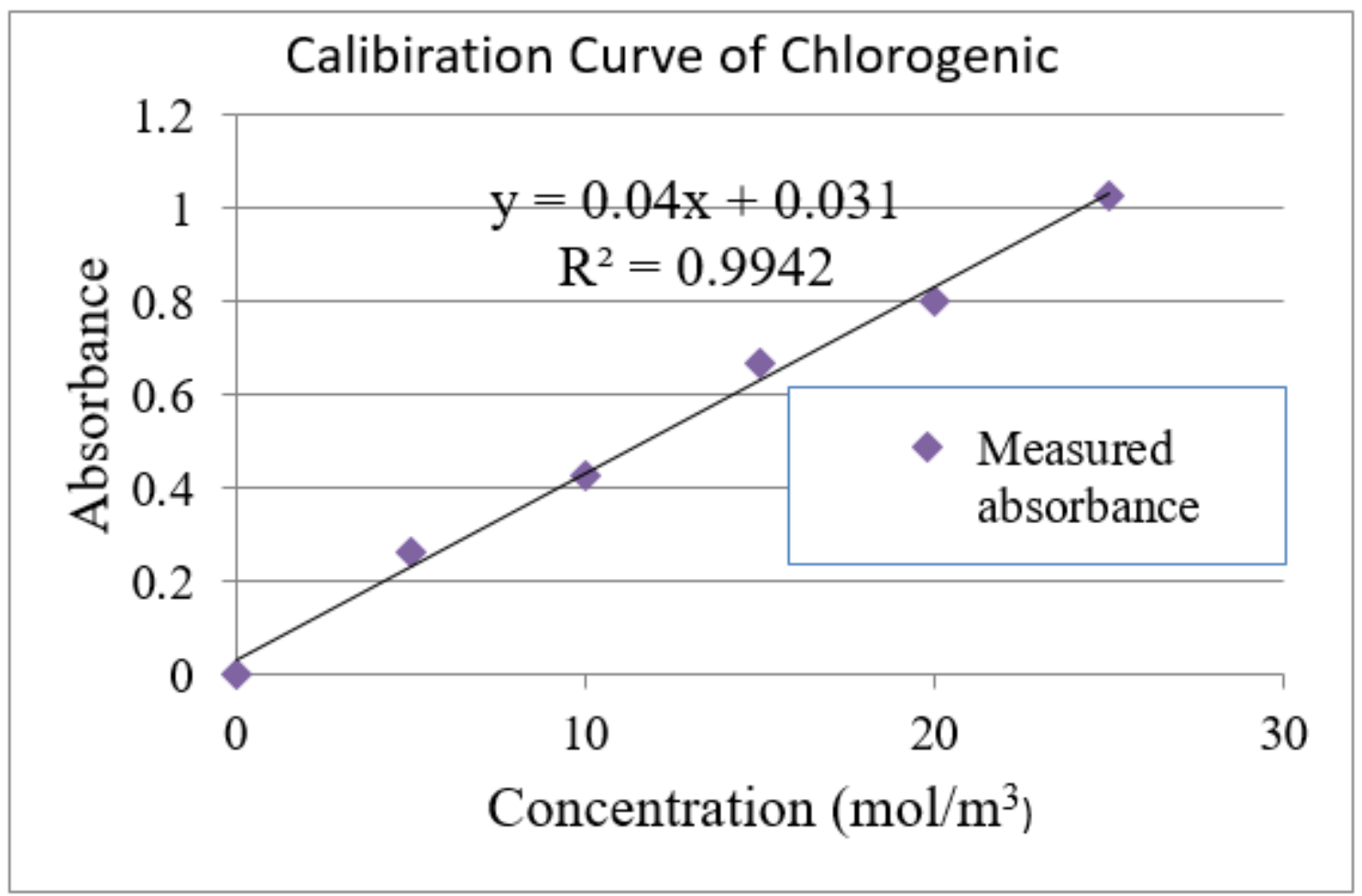

Figure 7

Linear plot of concentration versus Absorbance in Dichloromethane. 


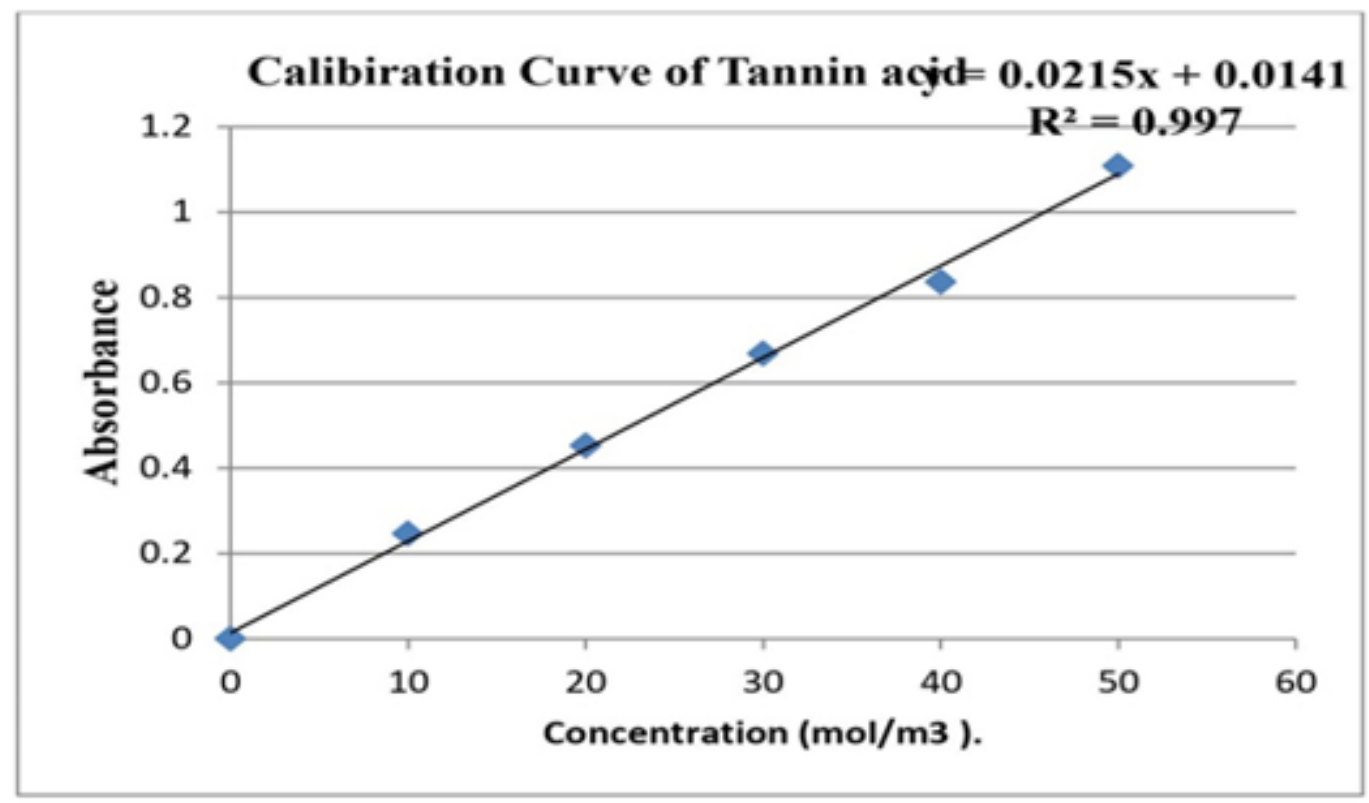

Figure 8

Linearn plot of concentration versus Absorbance in dichloromethane. 